\title{
Magnetic sphincter augmentation (MSA) in patients with hiatal hernia: clinical outcome and patterns of recurrence
}

\author{
Shahin Ayazi ${ }^{1}$ - $\cdot$ Nobel Chowdhury $^{1} \cdot$ Ali H. Zaidi $^{1} \cdot$ Kristy Chovanec $^{1} \cdot$ Yoshihiro Komatsu $^{1} \cdot$ Ashten N. Omstead $^{1}$. \\ Ping Zheng ${ }^{1} \cdot$ Toshitaka Hoppo $^{1} \cdot$ Blair A. Jobe ${ }^{1}$
}

Received: 8 April 2019 / Accepted: 26 June 2019 / Published online: 8 July 2019

(c) The Author(s) 2019

\begin{abstract}
Introduction Magnetic sphincter augmentation (MSA) is an effective treatment for patients with gastroesophageal reflux disease. In early studies, patients with a hiatal hernia $(\mathrm{HH}) \geq 3 \mathrm{~cm}$ were excluded from consideration for implantation and initially the FDA considered its use as "precautionary" in this context. This early approach has led to an attitude of hesitance among some surgeons to offer this therapy to patients with $\mathrm{HH}$. This study was designed to evaluate the impact of $\mathrm{HH}$ status on the outcome of MSA and to report the rate of HH recurrence after MSA.

Methods and procedures This is a retrospective review of prospectively collected data of patients who underwent MSA between June 2013 and August 2017. Baseline clinical and objective data were collected. Patients were divided into four groups based on $\mathrm{HH}$ status: no $\mathrm{HH}$, small $\mathrm{HH}(<3 \mathrm{~cm})$, large $\mathrm{HH}(\geq 3 \mathrm{~cm})$, and paraesophageal hernia (PEH). Patient satisfaction, GERD-HRQL and RSI data, freedom from PPI, need for postoperative dilation, length of hospitalization, 90-day readmission rate, need for device removal, and HH recurrence was compared between groups.

Results There were 350 patients [60\% female, mean (SD) age: $53.5(13.8)]$ who underwent MSA. There were $65(18.6 \%)$ with no HH, $205(58.6 \%)$ with small $\mathrm{HH}(<3 \mathrm{~cm}), 58(16.6 \%)$ with large $\mathrm{HH}(\geq 3 \mathrm{~cm})$ and $22(6.2 \%)$ with PEH. At a mean follow-up of 13.6 (10.4) months, the rate of outcome satisfaction was similar between the groups $(86 \%, 87.9 \%, 92.2 \%$ and $93.8 \%, p=0.72)$. This was also true for GERD-HRQL total score clinical improvement $(79.1 \%, 77.8 \%, 82 \%$ and $87.5 \%$, $p=0.77)$. The rate of postoperative dysphagia $(p=0.33)$ and freedom from PPIs $(p=0.96)$ were similar among the four groups. Duration of hospitalization was higher among those with a large HH or PEH, and only PEH patients had a higher 90 -day readmission rate $(p=0.0004)$. There was no difference between the need for dilation among groups $(p=0.13)$. The need for device removal ( $5 \%$ overall) was similar between the four groups $(p=0.28)$. HH recurrence was $10 \%$ in all groups combined, and only 7 of 240 (2.9\%) patients required reoperation; the majority of these patients underwent a minimal dissection approach (no hernia repair) at the index operation. The incidence of recurrent HH increased in direct correlation with the preoperative $\mathrm{HH}$ size $(0 \%, 10.1 \%, 16.6$ and $20 \%, p=0.032)$.

Conclusion In the largest series of MSA implantation, we demonstrate that the excellent outcomes and high degree of satisfaction after MSA are independent of the presence or size of HH. Despite higher rates of hernia recurrence in large $\mathrm{HH}$ and PEH patients, the rates of postoperative endoscopic intervention, and device removal is similar to those with no or small $\mathrm{HH}$. The minimal dissection approach to MSA should be abandoned.
\end{abstract}

Keywords Gastroesophageal reflux disease (GERD) $\cdot$ Hiatal hernia $\cdot$ Magnetic sphincter augmentation

This work was presented in the "Foregut Scientific Session" of the SAGES 2019 Annual Meeting. Program Number: S022, Session: SS04. April 3-6, 2019, Baltimore, MD.

Blair A. Jobe

blair.jobe@ahn.org

1 Esophageal and Lung Institute, Allegheny Health Network, 4815 Liberty Avenue, Suite 439, Pittsburgh, PA 15224, USA
Gastroesophageal reflux disease (GERD) is the most common foregut disease that affects about $10 \%$ of the western population [1-3]. In this chronic disease, both the crural contribution and intrinsic barrier function of the lower esophageal sphincter (LES) fails and allows reflux of abnormal amounts of gastric juice into the esophagus. The two main treatment options for patients with GERD are longterm acid suppression therapy with proton-pump inhibitors 
(PPI) or laparoscopic fundoplication. Medical acid suppression therapy is an effective first-line therapy in most patients. However, nearly $40 \%$ of patients experience breakthrough symptoms $[4,5]$. In addition, there are potential risks associated with PPIs including B12 vitamin deficiency, Clostridium difficile infection, community-acquired pneumonia, and osteoporosis [6-8]. Other consequences of prolonged PPI therapy include hypergastrinemia, enterochromaffin-like cell hyperplasia, and parietal cell hypertrophy, leading to rebound acid hypersecretion $[9,10]$.

Laparoscopic Nissen fundoplication is the surgical treatment option offered to patients whose condition has failed to respond to medical therapy or who desire to be free from dependence on medical therapy. However, this operation is underused due to the fears of long-term side effects such as gas bloat, inability to belch or vomit, and anatomic failure of the repair. The limitations of pharmacologic therapy and fundoplication leave many patients and clinicians in the difficult position to either tolerate a lifetime of drug dependence with incomplete symptom relief or to undergo a complex surgical procedure that is has been difficult to disseminate on a largescale, and may have considerable side effects.

Magnetic sphincter augmentation was developed to address the existing 'therapy gap' through a laparoscopic procedure, that does not alter gastric anatomy, augments the physiologic barrier to reflux, and is reversible. This procedure was designed to be a technically straightforward and highly reproducible outpatient procedure that centers on the implantation of a device. Because of this, multiple centers across the United States have reported a high degree of success with remarkably consistent clinical outcomes [11-15].

In early studies, patients with a hiatal hernia $(\mathrm{HH}) \geq 3 \mathrm{~cm}$ were excluded from consideration for implantation and initially the FDA considered its use as "precautionary" in this context [16]. This early approach has led to an attitude of hesitance among some surgeons to offer this therapy to patients with $\mathrm{HH}$, and a minimal dissection approach (no mediastinal dissection or cruralplasty) was recommended. Recent studies have demonstrated encouraging results in the use of MSA in patients with a larger size hiatal hernia $[17,18]$. However, there remains a paucity of data on the overall impact of hiatal hernia on the outcome of MSA. This study was designed to compare the outcome of MSA across the spectrum of hiatal hernias commonly encountered in the care of patients with GERD and to review the pattern of hiatal hernia recurrence.

\section{Methods}

\section{Study population}

This is a retrospective review of prospectively collected data of patients who underwent MSA at Allegheny Health
Network hospitals (Pittsburgh, PA) between June 2013 and August 2017. Approval was obtained from the Allegheny Health Network Institutional Review Board (IRB 2018-161) prior to the start of the study.

Inclusion criteria were symptomatic GERD patients 18 years or older with persistent GERD or laryngopharyngeal reflux symptoms despite maximal antisecretory therapy and objective evidence of reflux disease based on increased esophageal acid exposure on $\mathrm{pH}$ monitoring or a positive impedance-pH based on previously described criteria [19-21]. Patients with a previous history of esophageal or gastric surgery, gross anatomic abnormalities such as esophageal stricture, significant esophageal dysmotility or a known allergy to titanium were not included in this study.

\section{Preoperative assessment}

All patients completed a detailed clinical evaluation with a focus on their foregut symptoms and acid suppression medication use, and completed the Gastroesophageal Reflux Disease-Health Related Quality of Life (GERD-HRQL) and Reflux Symptom Index questionnaires [22, 23] while taking their usual dosing of antisecretory medication. The GERD-HRQL assesses GERD symptoms and patient satisfaction using a 0 to 5 rating scale. It is composed of ten questions relating to the severity of heartburn, regurgitation dysphagia, odynophagia, and bloating. The total GERD-HRQL score is calculated by summing the responses to 10 questions with scores ranging from 0 to 50 [22]. Similarly, the RSI is a validated and reproducible nine-item instrument (each item with a 0 to 5 rating scale) used in assessment of laryngopharyngeal reflux (LPR) symptom severity with a score $>13$ being abnormal. Patients completed an objective foregut evaluation prior to consideration for surgery. The routine preoperative objective assessment included the following tests:

1. Esophagogastroduodenoscopy (EGD) with biopsy: to assess the presence of esophagitis, Barrett's esophagus and the presence and size of a hiatal hernia. The size of $\mathrm{HH}$ was recorded in centimeters based on the distance from the gastroesophageal junction to the crural impression. Patients were divided into 4 groups based on $\mathrm{HH}$ status: no $\mathrm{HH}$, small $\mathrm{HH}(<3 \mathrm{~cm})$, large $\mathrm{HH}(\geq 3 \mathrm{~cm})$, and paraesophageal hernia (PEH). Small and large $\mathrm{HH}$ (Type I) was defined as axial displacement of the gastroesophageal junction (GEJ) and proximal stomach into the chest with all herniated stomach being distal to the GEJ. Paraesophageal hernia (Type III) was defined when both the GEJ and stomach were located intrathoracically with a portion or entire herniated stomach located proximal to the GEJ or in the presence of organoaxial volvulus ("upside down stomach"). 
2. High-resolution impedance manometry (HRIM): this test was performed using high-resolution manometry (4.2-mm diameter; Medtronic Inc., MN), equipped with 36 pressure transducers $(1 \mathrm{~cm}$ apart) to assess the esophageal body peristalsis (organization and pressure) and upper and lower esophageal sphincter pressure, position and length as previously described [24].

3. Esophageal $\mathrm{pH}$ or impedance-pH monitoring: these tests were performed selectively using either Bravo $\mathrm{pH}$ monitoring (Medtronics, Shoreview, MN, USA) or multichannel intraluminal impedance (MII) $\mathrm{pH}$ monitoring (Sandhill Scientific Inc, Highlands Ranch CO) [21, 25]. Prior to $\mathrm{pH}$ testing proton pump inhibitors were discontinued for 10 days. A DeMeester score $>14.7$ was considered as abnormal distal esophageal acid exposure. Impedance-pH testing was used in patients with predominate symptoms of laryngopharyngeal reflux with or without typical reflux symptoms using previously described criteria [21].

4. Videoesophagram (VEG): this imaging study was done to evaluate gross pharyngeal and esophageal motility, and to further delineate the anatomy and assess for any potential mass or mucosal lesions, diverticulum, and to evaluate hiatal hernia and esophageal stricture or scarring.

\section{Postoperative and outcome assessment}

Subjective postoperative outcomes were evaluated at routine visits at 2 weeks, 6 weeks, 3 months, and then yearly after surgery. Patients were assessed for resolution of their reflux symptoms, use of antisecretory medications, and procedurerelated complications. Length of hospital stay, need for readmission within 90 days after surgery, and need for postoperative dilation and device removal were also recorded. Patients were asked to complete GERD-HRQL and RSI questionnaires at their 6 month and yearly visits. A 50\% improvement in the total GERD-HRQL score compared with the baseline on antisecretory therapy was considered clinically significant in this study. Using the RSI, late postoperative dysphagia was defined as a postoperative dysphagia score $\geq 3$ on the 'difficulty swallowing' item at $\geq 8$ weeks after MSA.

At 1-year following MSA, patients were approached for objective foregut evaluation using the same tests employed in the preoperative evaluation. Recurrence of $\mathrm{HH}$ was determined based on follow-up upper endoscopy at 1-year follow-up or if the patient presented with suggestive symptoms prior to that time [26].

A recurrence was considered present if the GEJ was found to be proximal to the crural impressions on either anterograde or retroflexion endoscopic view.

\section{Device and surgical procedure}

The LINX device (Ethicon, Johnson \& Johnson, Shoreview, $\mathrm{MN}$ ) consists of a series of titanium beads with magnetic cores hermetically sealed inside. The beads are interlinked with independent titanium wires to form a flexible and expandable ring with a 'Roman arch' configuration. Each bead can move independently of the adjacent beads, creating a dynamic implant that mimics the physiological movement of the esophagus without limiting its range of motion. The device is manufactured in different sizes, from 13 to 17 beads, and is capable of nearly doubling its diameter when all beads are separated.

This procedure is performed laparoscopically and consists of complete posterior mediastinal esophageal mobilization with restoration of intraabdominal esophageal length $(\geq 3 \mathrm{~cm}$ ), interrupted posterior crural closure (without pledgets or mesh) and device placement at the level of the GEJ with the posterior vagus nerve trunk located on the outside of the magnetic ring.

Early in our experience, a 'minimal dissection' technique was used in patients with little to no $\mathrm{HH}$; this approach does not include mediastinal esophageal dissection, the phrenoesophageal ligament is left intact, and there is no crural closure. A small window is created within the retroesophageal space, and the device is placed around the GEJ.

A sizing procedure, which assesses esophageal circumference, is performed prior to selecting the size of device. This approach is used in all patients regardless of whether there is a preoperative diagnosis of hiatal hernia. Many patients have transverse widening of the hiatal opening with minimal axial displacement and our approach is focused on restoring the crural contribution of the antireflux barrier during MSA placement. Intraoperative esophagogastroscopy is performed in order to assist in identifying the anatomic GEJ and to assess device position (Fig. 1).

\section{Statistical analysis}

Values are expressed as either mean with standard deviation (SD) or median with interquartile range (IQR) when appropriate. Statistical analysis was performed by means of nonparametric Mann-Whitney $U$ test, Wilcoxon signedrank test, and Person's Chi-square test when appropriate. A $p$ value $<0.05$ was considered significant. Statistical analysis was performed using SAS software (SAS Institute Inc., Cary, N.C.).

Patients were divided into four groups based on $\mathrm{HH}$ status: no $\mathrm{HH}$, small $\mathrm{HH}(<3 \mathrm{~cm})$, large $\mathrm{HH}(\geq 3 \mathrm{~cm})$, and paraesophageal hernia (PEH). Patient satisfaction, GERD-HRQL data, freedom from PPI, need for postoperative dilation, length of hospitalization, 90-day readmission 

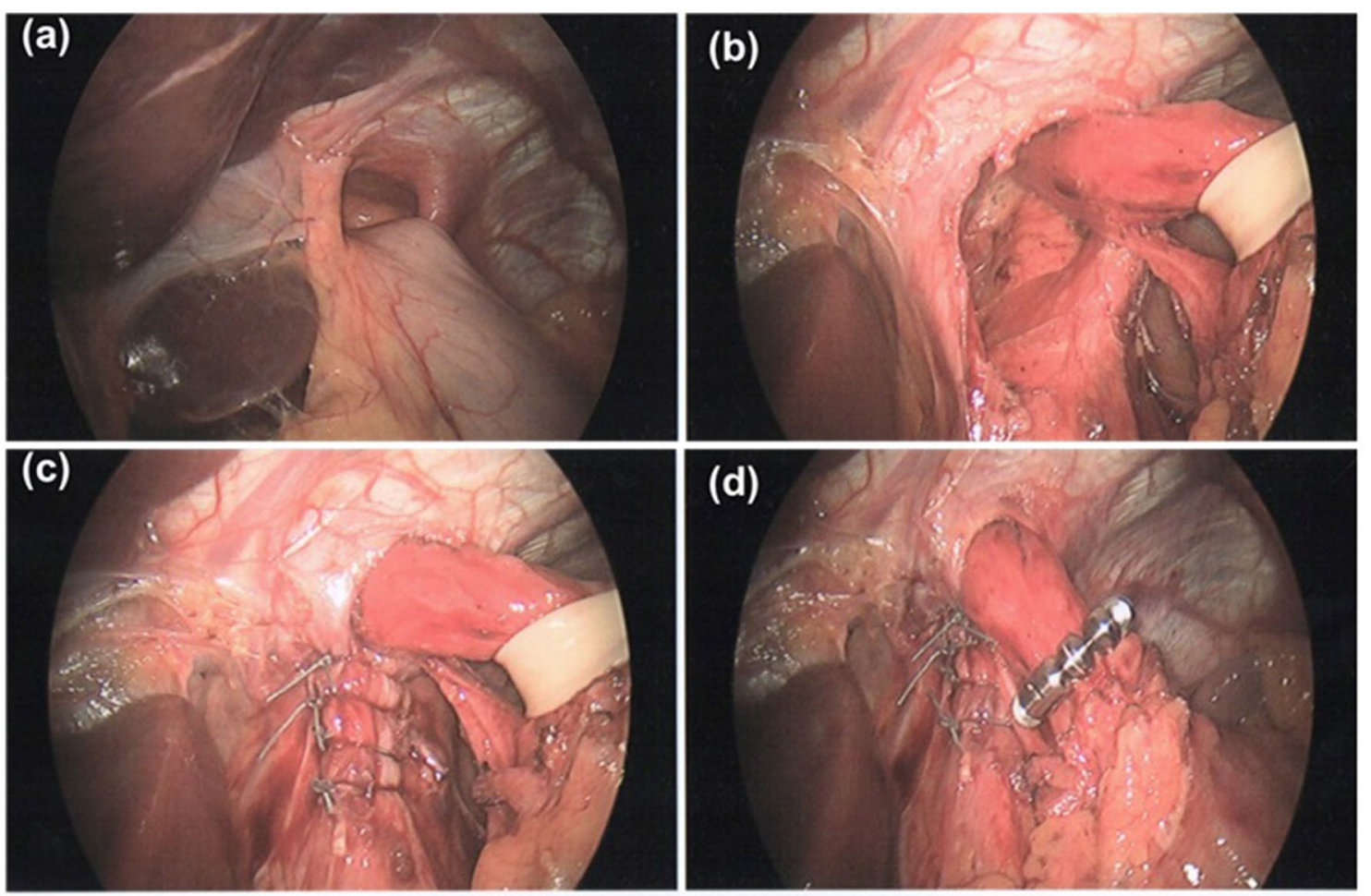

Fig. 1 Steps of hernia repair and magnetic sphincter augmentation in a patient with large PEH

rate, the need for device removal, and $\mathrm{HH}$ recurrence were compared between groups.

\section{Results}

There were 350 patients who underwent magnetic sphincter augmentation during the study period and were included in this analysis. Patients were mostly in the fifth decade of life and there were more women than men (Table 1).

\section{Preoperative status of hiatal hernia and outcome}

A total of 285 patients were found to have a hiatal hernia on their preoperative endoscopy. Of these, 205 (71.9\%) had a small hernia, 58 (20.4\%) had a large hernia and 22 (7.7\%) had a paraesophageal hernia. Of the 65 patients with no evidence of hernia on preoperative evaluation, 28 (30\%) were found to have transverse crural separation and a small "dimple" within the phrenoesophageal ligament anteriorly as viewed laparoscopically. These patients remained classified within the no hernia group and 38 patients underwent the minimal dissection approach early in our experience.

Patients with a large or paraesophageal hernia were significantly older compared to those with a small or no hernia [60.4 (10.7) vs. $51.5(14), p<0.0001]$. There was also
Table 1 Baseline demographic and clinical characteristics

\begin{tabular}{lc}
\hline Characteristics & $N(\%)$ \\
\hline Age (year) & \\
Mean (SD) & $53.5(13.8)$ \\
Gender & \\
Male & $141(40.3 \%)$ \\
Female & $209(59.7 \%)$ \\
BMI & \\
Mean (SD) & $29.2(4.7)$ \\
PPI use & $251(89 \%)$ \\
DeMeester score & \\
Mean (SD) & $32.6(27.5)$ \\
$N(\%)$ with abnormal score $(\geq 14.72)$ & $144(74.6 \%)$ \\
Hiatal hernia & \\
Yes & $285(81.4 \%)$ \\
No & $65(18.6 \%)$ \\
Size and type of hernia & \\
Small $(\leq 3 \mathrm{~cm})$ & $205(71.9 \%)$ \\
Large $(\geq 3 \mathrm{~cm})$ & $58(20.4 \%)$ \\
PEH & $22(7.7 \%)$ \\
\hline
\end{tabular}

a higher percentage of women among those with large or paraesophageal hernia (70\% vs. $56.7 \%, p=0.037)$.

At a mean follow-up of 13.6 (10.4) months, the rate of outcome satisfaction was high and similar between the four 
Table 2 Subjective and objective outcome measures 1 year after MSA

\begin{tabular}{|c|c|c|c|c|c|c|}
\hline \multirow[t]{2}{*}{ Measurement } & \multirow[t]{2}{*}{$N(\%)$} & \multicolumn{4}{|c|}{ Baseline hiatal hernia status } & \multirow[t]{2}{*}{$p$ Value } \\
\hline & & $\begin{array}{l}\text { None } \\
N(\%)\end{array}$ & $\begin{array}{l}\text { Small } \\
N(\%)\end{array}$ & $\begin{array}{l}\text { Large } \\
N(\%)\end{array}$ & $\begin{array}{l}\mathrm{PEH} \\
N(\%)\end{array}$ & \\
\hline Total & $350(100.0)$ & 65 (18.6) & $205(58.6)$ & $58(16.6)$ & $22(6.2)$ & N/A \\
\hline Satisfaction from surgery & 277 & & & & & \\
\hline No & $31(11.2 \%)$ & $6(13.3 \%)$ & $20(12.1 \%)$ & $4(7.8 \%)$ & $1(6.2 \%)$ & 0.73 \\
\hline Yes & $246(88.8 \%)$ & $39(86.7 \%)$ & $145(87.9 \%)$ & $47(92.2 \%)$ & $15(93.8 \%)$ & \\
\hline $\begin{array}{l}\text { GERD-HRQL total score clinical } \\
\text { improvement }\end{array}$ & 280 & & & & & \\
\hline No & $58(20.7 \%)$ & $9(20.9 \%)$ & $38(22.2 \%)$ & $9(18.0 \%)$ & $2(12.5 \%)$ & 0.77 \\
\hline Yes & $222(79.3 \%)$ & $34(79.1 \%)$ & $133(77.8 \%)$ & $41(82.0 \%)$ & $14(87.5 \%)$ & \\
\hline Normalization of acid exposure & 193 & & & & & \\
\hline DeMeester score $<14.7$ & $143(74.1 \%)$ & $27(71.1 \%)$ & $88(79.3 \%)$ & $21(65.6 \%)$ & $7(58.3 \%)$ & 0.21 \\
\hline Freedom from PPI use & 282 & & & & & \\
\hline Yes & $259(91.8 \%)$ & $41(93.2 \%)$ & $156(91.8 \%)$ & $47(90.4 \%)$ & $15(93.8 \%)$ & 0.96 \\
\hline No & $23(8.2 \%)$ & $3(6.8 \%)$ & $14(8.2 \%)$ & $5(9.6 \%)$ & $1(6.2 \%)$ & \\
\hline
\end{tabular}

Table 3 Hospital stay and complication and readmission rates (within 90 days)

\begin{tabular}{|c|c|c|c|c|c|c|}
\hline \multirow[t]{2}{*}{ Measurement } & \multirow[t]{2}{*}{$N(\%)$} & \multicolumn{4}{|c|}{ Baseline hiatal hernia status } & \multirow[t]{2}{*}{$p$ Value } \\
\hline & & $\begin{array}{l}\text { None } \\
N(\%)\end{array}$ & $\begin{array}{l}\text { Small } \\
N(\%)\end{array}$ & $\begin{array}{l}\text { Large } \\
N(\%)\end{array}$ & $\begin{array}{l}\text { PEH } \\
N(\%)\end{array}$ & \\
\hline Total & $350(100.0 \%)$ & $65(18.6 \%)$ & $205(58.6 \%)$ & $58(16.6 \%)$ & $22(6.2 \%)$ & \\
\hline \multicolumn{7}{|l|}{ Hospitalization } \\
\hline Same day discharge & $323(92.3 \%)$ & $61(93.9 \%)$ & $196(95.6 \%)$ & $49(84.5 \%)$ & $17(77.3 \%)$ & $p=0.002$ \\
\hline$\geq$ One day hospital stay & $27(7.7 \%)$ & $4(6.1 \%)$ & $9(4.4 \%)$ & $9(15.5 \%)$ & $5(22.7 \%)$ & \\
\hline Readmission within 90 days & $19(5.4 \%)$ & $0(0.0 \%)$ & $14(6.8 \%)$ & $2(3.5 \%)$ & $3(13.7 \%)$ & $p=0.049$ \\
\hline Major complications ${ }^{\mathrm{a}}$ & $2(0.6 \%)$ & $0(0.0 \%)$ & $0(0.0 \%)$ & $2(3.4 \%)$ & $0(0.0 \%)$ & \\
\hline Minor complications ${ }^{\mathrm{b}}$ & $37(10.6 \%)$ & $2(3.1 \%)$ & $23(11.2 \%)$ & $6(10.4 \%)$ & $6(27.3 \%)$ & \\
\hline Overall complications & $39(11.1 \%)$ & $2(3.1 \%)$ & $23(11.2 \%)$ & $8(13.8 \%)$ & $6(27.3 \%)$ & $p=0.015$ \\
\hline
\end{tabular}

${ }^{a}$ Major complications include $\mathrm{CO}_{2}$ retention requiring re-intubation $(n=1)$ and mediastinal abscess requiring drainage and IV antibiotic $(n=1)$

${ }^{\mathrm{b}}$ Minor complications include poor postoperative pain control $(n=2)$, significant nausea during immediate postoperative period $(n=3)$, hypoxia requiring supplemental oxygenation $(n=6)$, lethargy $(n=2)$, abdominal pain requiring further evaluation $(n=5)$, persistent nausea and vomiting $n=(8)$, abdominal wall hematoma at gastric pacer insertion site $(n=1)$, DVT $(n=1)$, urinary retention $(n=1)$, and dyspnea requiring further work-up $(n=2)$ groups $(p=0.72)$. This was also true for GERD-HRQL total score clinical improvement $(p=0.77)$, the rate of freedom from PPI ( $p=0.96)$, and normalization of distal esophageal acid exposure $(p=0.21)$ (Table 2$)$.

\section{Perioperative complications and hospital stay}

Ninety percent of the patients with no hernia or a small hernia were discharged home on the same day of surgery. In contrast $76 \%$ of those with a large or paraoesophageal hernia were discharged home on the same day (Table 3). The reasons for overnight stay were: poor post-op pain control $(n=2), \mathrm{CO}_{2}$ retention and need for re-intubation $(n=1)$, significant post-op nausea $(n=3)$, need for supplemental oxygen $(n=6)$ and lethargy $(n=2)$. In the remaining 13 patients, the overnight observation was due to patient request, presence of comorbidities or advanced age.

A total of 19 patients required readmission within 90 days after surgery. One patient was readmitted three times; this patient also had implantation of a gastric stimulator at the time of MSA. This patient required two admissions for persistent nausea and vomiting and one admission for hematoma at the site of gastric stimulator within the anterior abdominal wall. Two patients required two readmissions and the remaining patients were readmitted only once after MSA (Table 3). 
Table 4 Rate of dysphagia, need for dilation or device removal

\begin{tabular}{|c|c|c|c|c|c|c|}
\hline \multirow[t]{2}{*}{ Measurement } & \multirow[t]{2}{*}{$N(\%)$} & \multicolumn{4}{|c|}{ Baseline hiatal hernia status } & \multirow[t]{2}{*}{$p$ Value } \\
\hline & & $\begin{array}{l}\text { None } \\
N(\%)\end{array}$ & $\begin{array}{l}\text { Small } \\
N(\%)\end{array}$ & $\begin{array}{l}\text { Large } \\
N(\%)\end{array}$ & $\begin{array}{l}\mathrm{PEH} \\
N(\%)\end{array}$ & \\
\hline Dysphagia & $41(15.3 \%)$ & $6(15.8 \%)$ & $31(15.7 \%)$ & $3(5.8 \%)$ & $1(5.9 \%)$ & 0.08 \\
\hline $\begin{array}{l}\text { Need for endo- } \\
\text { scopic dilation }\end{array}$ & $82(23.4 \%)$ & $13(20.0 \%)$ & $54(26.3 \%)$ & $14(24.1 \%)$ & $1(4.5 \%)$ & 0.12 \\
\hline Device removal & $18(5.1 \%)$ & $4(6.1 \%)$ & $13(6.4 \%)$ & $1(1.7 \%)$ & $0(0.0 \%)$ & 0.28 \\
\hline
\end{tabular}

Table 5 Classification of symptomatic recurrence of hiatal hernia after MSA and proposed management

Type I-a HH recurrence with properly placed device in relation GEJ

Type I-b HH recurrence with position of device located too proximal to GEJ

Type I-c HH recurrence with location of device on cardia or proximal stomach

Type II ${ }^{\mathrm{a}}$ Paraesophageal re-herniation with GEJ in intraabdominal location

Type III ${ }^{\mathrm{a}}$ Paraesophageal re-herniation with stomach and GEJ located intrathoracically
Repair hernia and leave the device in position

Endoscopic dilation under fluoroscopy and short course of steroid (if recurrence is small and occurs within 3 months from surgery)

If large symptomatic recurrence, go directly to $\mathrm{HH}$ repair and replace device

If normal or mildly reduced LES pressure and/or length on preoperative manometry, repair $\mathrm{HH}$ and remove device without further intervention

If absent or markedly reduced LES pressure and/or length on preoperative manometry, repair hernia and replace device or perform fundoplication

Device in proper position at GEJ: Repair hernia \pm biologic mesh and leave device in place

Device in wrong location (too proximal or too distal) in relation to GEJ: Repair hernia \pm biologic mesh and replace device or perform fundoplication

Device in proper position at GEJ: Repair hernia \pm biologic mesh and leave device in place

Device in wrong location in relation to GEJ (too proximal or too distal): Repair hernia \pm biologic mesh and replace device or perform fundoplication

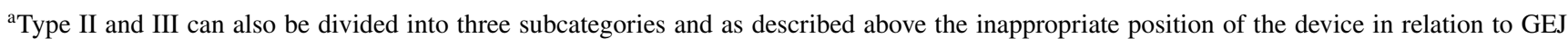
will require device replacement

\section{Postoperative dysphagia and need for intervention}

There was an improvement in the overall prevalence of dysphagia when compared to baseline ( 11.7 vs. $35 \%, p<0.001)$. The rate of postoperative dysphagia was similar among the four groups ( $p=0.33$, Table 4$)$ and there was no difference between the need for dilation among groups $(p=0.13)$. The need for device removal (5\% overall) was similar between the four groups $(p=0.28)$. All the removals were for persistent dysphagia or esophageal spasm unresponsive to endoscopic dilation. There were no device erosions in this series.

\section{Objective follow-up and hernia recurrence}

A total of 240 of 350 (69\%) patients underwent upper endoscopy on their annual follow-up visit. Based on the observed patterns of $\mathrm{HH}$ recurrence and insights obtained from reoperation, we have established a classification system and proposed management strategy (Table 5). Radiologic and endoscopic appearance of a type I-b hernia recurrence is shown in Fig. 2 and radiologic images of a patient with type III recurrence are shown in Fig. 3. The rate of $\mathrm{HH}$ recurrence on upper endoscopy was $10 \%(n=24)$ in all groups combined. Of these, 20 (83.3\%) had a small hernia, 1 (4.2\%) had a large hernia and $3(12.5 \%)$ had a paraesophageal hernia. Recurrence rate increased in a stepwise fashion with an increase in preoperative $\mathrm{HH}$ size $(0 \%, 10.1 \%, 16.6 \%$ and $20 \%, p=0.032$, Fig. 4). Patients with a minimal dissection had a higher hiatal hernia recurrence rate compared to those with a full dissection $(21 \%$ vs. $7.9 \%, p=0.033)$.

Of 24 patients found to have hiatal hernia recurrence on endoscopy, 7 required reoperation (Table 6). Patient with minimal dissection was more likely to require reoperation compared to those with a full dissection $(10.5 \%$ vs. $1.5 \%$, $p=0.0133$ ). Factors associated with recurrence of hernia in these 7 patients were increase in body mass index after MSA, participation in activities or conditions that increase intrabdominal pressure, and the minimal dissection approach to MSA. We observed that the majority of patients with symptomatic recurrence presented with new onset dysphagia 

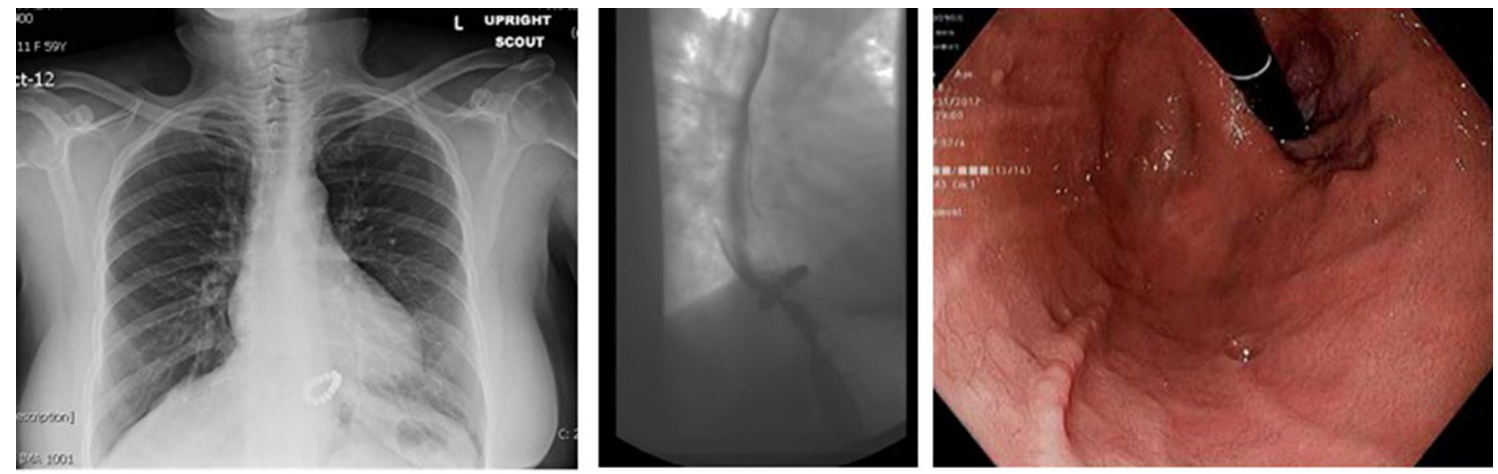

Fig. 2 Radiologic and endoscopic appearance of a type I-b hernia recurrence after MSA with minimal dissection. This patient underwent endoscopic balloon dilation of the GEJ and a short course of steroid with resolution of her symptoms
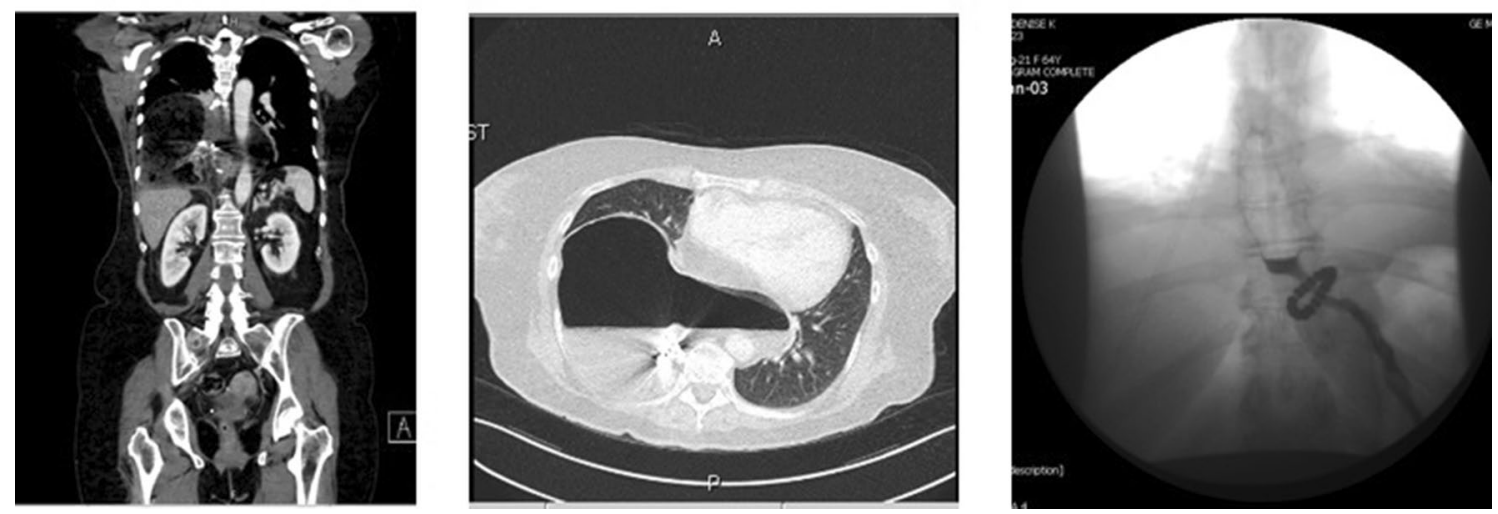

Fig. 3 CT scan of a patient with type III recurrence. Patient underwent reoperation for repair of PEH and LINX device was left in position. The postoperative esophagram after reoperation demonstrates an appropriately positioned LINX® and no herniation

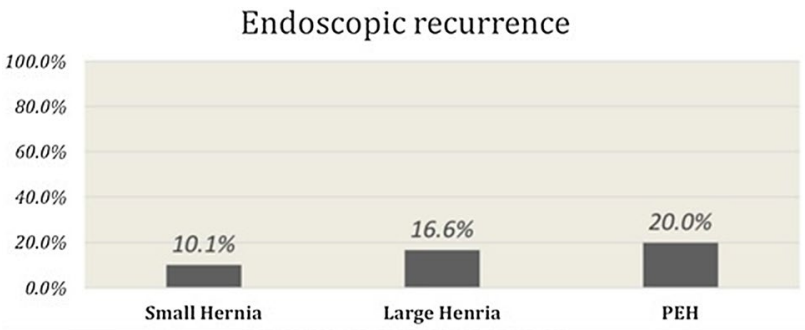

Fig. 4 Incidence (\%) of endoscopic hiatal hernia recurrence across the groups

with or without upper abdominal pain; and 2 patients that originally presented with cough had return of this symptom with recurrence.

Of the patients that returned for high-resolution manometry $(n=95)$ at 1 -year following MSA, there was no difference in esophageal function (peristalsis or pressure) when compared to preoperative values. Of note, with surgical correction of PEH and MSA, there was marked improvement in preoperative incomplete bolus clearance in this group (Table 7).

\section{Discussion}

Reflux disease and its complications are the consequences of progressive anatomic and mechanical defects. Hiatal hernia plays an important role in this disease process and its repair in addition to fundoplication is of critical importance in every antireflux surgery [30]. At the outset, MSA was designed to support a partially defective LES and prevent its effacement with gastric distention and increases in intraabdominal pressure. The original intent of MSA was placement in the earlier stages of GERD (without hiatal derangement) to stop symptoms and prevent progression to a large hiatal hernia with severe bi-positional volume reflux.

As more MSA procedures were performed in early stage GERD patients, it became evident that many HH were subclinical and only discovered at the time surgery in the form 


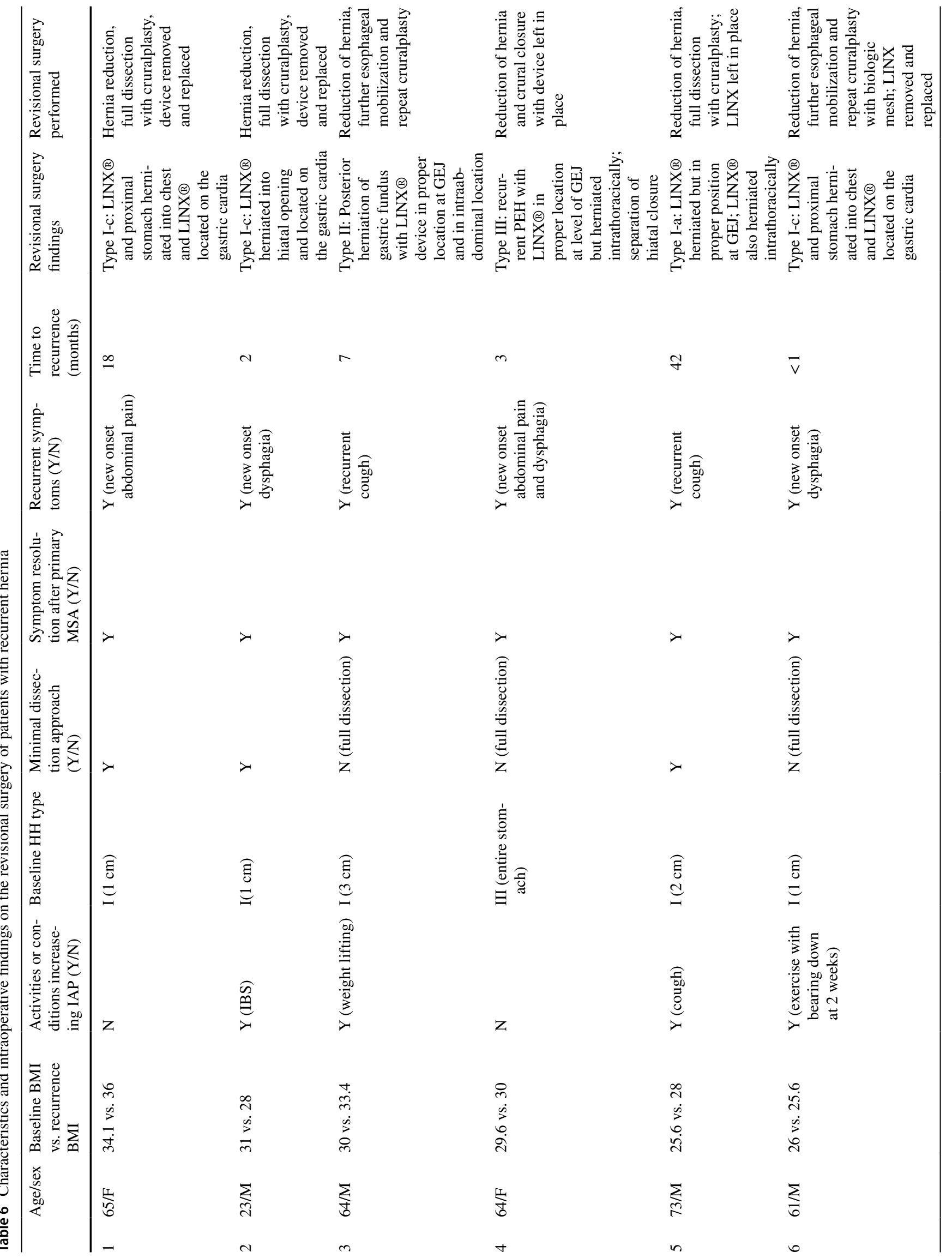




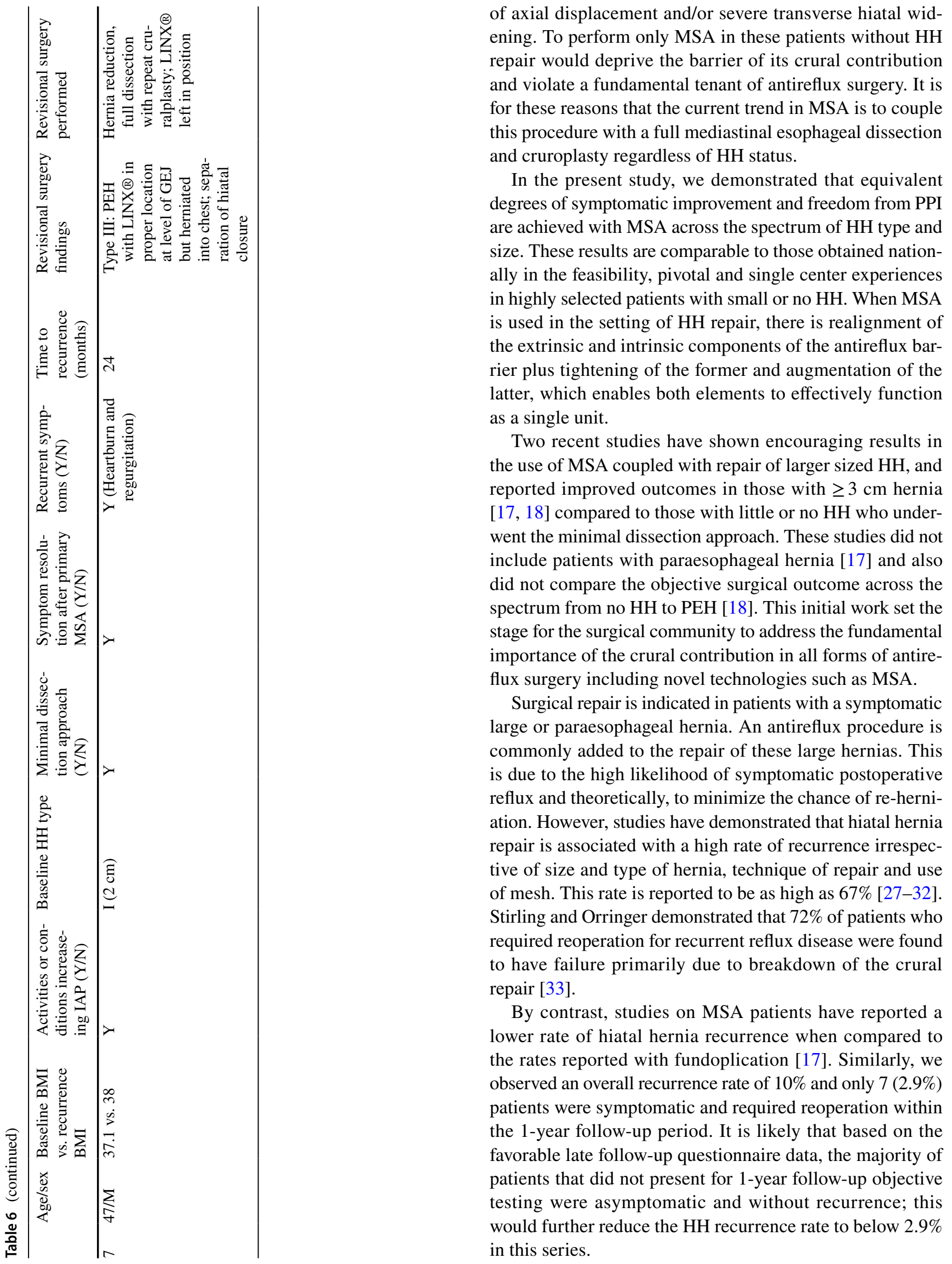


Table 7 Preoperative and postoperative esophageal body manometric characteristic across the four groups

\begin{tabular}{clllll}
\hline Measurement & \multicolumn{2}{l}{ Baseline hiatal hernia status } & \multirow{2}{*}{$p$ Value } \\
\cline { 2 - 4 } & $\begin{array}{l}\text { None } \\
\text { Mean (SD) }\end{array}$ & $\begin{array}{l}\text { Small } \\
\text { Mean (SD) }\end{array}$ & $\begin{array}{l}\text { Large } \\
\text { Mean (SD) }\end{array}$ & $\begin{array}{l}\text { PEH } \\
\text { Mean (SD) }\end{array}$ & \\
\hline Mean wave amplitude (mmHg) & & & & & \\
Preoperative value, mean (SD) & $101(48)$ & $85(38)$ & $88(47)$ & $85(34)$ & 0.45 \\
Postoperative value mean (SD) & $122(54)$ & $100(38)$ & $93(39)$ & $83(37)$ & 0.24 \\
Mean DCI (mmHg.s.cm) & & & & & \\
Preoperative value, mean (SD) & $2368(1971)$ & $1881(1380)$ & $2201(2432)$ & $1332(708)$ & 0.24 \\
Postoperative value mean (SD) & $3452(2379)$ & $2231(1313)$ & $2848(3009)$ & $1645(919)$ & 0.32 \\
$\%$ Peristaltic waves & & & & & \\
Preoperative value, mean (SD) & $91(17)$ & $90(18)$ & $89(18)$ & $95(9)$ & 0.59 \\
Postoperative value Mean (SD) & $90(15)$ & $88(19)$ & $88(17)$ & $88(13)$ & 0.97 \\
$\%$ Incomplete bolus clearance & & & & & \\
Preoperative value, mean (SD) & $16(27)$ & $22(33)$ & $32(37)$ & $43(45)$ & 0.007 \\
Postoperative value mean (SD) & $15(22)$ & $29(36)$ & $30(36)$ & $16(21)$ & 0.61 \\
\hline
\end{tabular}

Recurrence rate increased in a stepwise fashion with an increase in preoperative $\mathrm{HH}$ size; however, it is interesting to note that most of the patients that required reoperation had a smaller size type I hernia and underwent the minimal dissection approach. Although the patients who underwent minimal dissection had a lower rate of hiatal hernia on their preoperative EGD, they had a higher rate of hiatal hernia recurrence requiring reoperation compared to those with a full dissection $(10.5 \%$ vs. $1.9 \%, p=0.013)$. Therefore, the minimal dissection approach to MSA should be abandoned.

Two explanations for the lower rate of recurrence after MSA have been proposed [17]. One is the preserved ability to belch after MSA thereby enabling consistent gastric decompression. This ability is lost after a Nissen fundoplication resulting in elevation in intragastric pressure, which imposes external force on the hiatus and fundoplication during the healing process and beyond. The second explanation is that the titanium device may provide a beneficial inflammatory response with subsequent scarring, thereby solidifying the hiatal closure and securing the GEJ in an intraabdominal location.

Our re-operative experience on patients after MSA supports this supposition, and we observed robust scarring around the device, GEJ, and crura during removal for dysphagia. Examination of tissues adjacent to orthopedic titanium plates has shown a chronic and sustained inflammatory response with abundant macrophages and fibroblasts [34]. This reaction may represent a benefit of MSA over Nissen fundoplication in terms of prevention of migration as well as reinforcement of the hiatal closure.

Our results establish that the application of MSA in the $\mathrm{HH}$ patient is safe with overall and major complication rates of $11 \%$ and $0.6 \%$, respectively. However, overall complications, length of stay, and 90-day readmission rates were higher in patients with large and paraesophageal hernia. In comparison with other groups, large and paraesophageal hernia groups of patients were older and had more co-morbid conditions than patients with small or no hernia. Using the National Surgical Quality Improvement Program (NSQIP) database, Molena and colleagues found advanced age to be associated with increased rates of 30-day morbidity, mortality, and length of stay in patients undergoing antireflux surgery [35].

We studied the impact of hiatal hernia in the largest series of patients with objective follow-up data. This study however is limited by its retrospective nature and lack of objective follow-up in $100 \%$ of the patients. Further, the surgeries were done in a high-volume center by surgeons with a focused foregut practice and in patients who underwent a detailed preoperative evaluation. It is possible that these results may not reflect broader clinical practice.

\section{Conclusion}

In the largest series of MSA implantation, we demonstrate that the excellent outcomes and high degree of satisfaction after MSA are independent of the presence or size of HH. Despite higher rates of hernia recurrence in large $\mathrm{HH}$ and $\mathrm{PEH}$ patients, the rates of postoperative endoscopic intervention, and device removal is similar to those with no or small HH. Patients with a minimal dissection have a higher rate of recurrent $\mathrm{HH}$ and are more likely to require reoperation compared to those with a full 
dissection. Therefore, the minimal dissection approach to MSA should be abandoned.

\section{Compliance with ethical standards}

Disclosures Dr. Blair A. Jobe is on the scientific advisory board of Johnson and Johnson and Medtronic and receives consulting fee. Drs. Shahin Ayazi, Nobel Chowdhury, Ali H. Zaidi, Kristy Chovanec, Yoshihiro Komatsu, Ashten N. Omstead, Ping Zheng and Toshitaka Hoppo have no conflicts of interest or financial ties to disclose.

Open Access This article is distributed under the terms of the Creative Commons Attribution 4.0 International License (http://creativeco mmons.org/licenses/by/4.0/), which permits unrestricted use, distribution, and reproduction in any medium, provided you give appropriate credit to the original author(s) and the source, provide a link to the Creative Commons license, and indicate if changes were made.

\section{References}

1. El-Serag HB, Sweet S, Winchester CC, Dent J (2014) Update on the epidemiology of gastro-oesophageal reflux disease: a systematic review. Gut 63(6):871-880

2. Fedorak RN, Veldhuyzen ZS, Bridges R (2010) Canadian Digestive Health Foundation public impact series: gastroesophageal reflux disease in Canada: incidence, prevalence, and direct and indirect economic impact. Can J Gastroenterol 24:431-434

3. Everhart JE, Ruhl CE (2009) Burden of digestive diseases in the United States part I: overall and upper gastrointestinal diseases. Gastroenterology 136(2):376-386

4. Fass R, Sifrim D (2009) Management of heartburn not responding to proton pump inhibitors. Gut 58(2):295-309

5. Zerbib F, Sifrim D, Tutuian R, Attwood S, Lundell L (2013) Modern medical and surgical management of difficult-to-treat GORD. United Eur Gastroenterol J 1(1):21-31

6. Katz PO, Gerson LB, Vela MF (2013) Guidelines for the diagnosis and management of gastroesophageal reflux disease. Am J Gastroenterol 108:308-328

7. Valuck RJ, Ruscin JM (2004) A case-control study on adverse effects: $\mathrm{H} 2$ blocker or proton pump inhibitor use and risk of vitamin B12 deficiency in older adults. J Clin Epidemiol 57(4):422-428

8. Andersen BN, Johansen PB, Abrahamsen B (2016) Proton pump inhibitors and osteoporosis. Curr Opin Rheumatol 28(4):420-425

9. Heidelbaugh JJ, Metz DC, Yang YX (2012) Proton pump inhibitors: are they overutilised in clinical practice and do they pose significant risk? Int J Clin Pract 66(6):582-591

10. McColl KEL, Gillen D (2009) Evidence that proton-pump inhibitor therapy induces the symptoms it is used to treat. Gastroenterology 137(1):20-22

11. Bonavina L, DeMeester TR, Ganz RA (2012) LINX $\left({ }^{\mathrm{TM}}\right)$ Reflux Management System: magnetic sphincter augmentation in the treatment of gastroesophageal reflux disease. Expert Rev Gastroenterol Hepatol 6(6):667-674

12. Rieder E, Riegler M, Simić AP, Skrobić OM, Bonavina L, Gurski R, Schoppmann SF (2018) Alternative therapies for GERD: a way to personalized antireflux surgery. Ann N Y Acad Sci 1434(1):360-369

13. Asti E, Aiolfi A, Lazzari V, Sironi A, Porta M, Bonavina L (2018) Magnetic sphincter augmentation for gastroesophageal reflux disease: review of clinical studies. Updates Surg 70(3):323-330

14. Reynolds JL, Zehetner J, Wu P, Shah S, Bildzukewicz N, Lipham JC (2015) Laparoscopic magnetic sphincter augmentation vs laparoscopic Nissen fundoplication: a matched-pair analysis of 100 patients. J Am Coll Surg 221(1):123-128

15. Bell R, Lipham J, Louie B, Williams V, Luketich J, Hill M, Katz P (2019) Laparoscopic magnetic sphincter augmentation versus double-dose proton pump inhibitors for management of moderateto-severe regurgitation in GERD: a randomized controlled trial. Gastrointest Endosc 89(1):14-22.e1

16. Ganz RA, Peters JH, Horgan S, Bemelman WA, Dunst CM (2013) Esophageal sphincter device for gastroesophageal reflux disease. $\mathrm{N}$ Engl J Med 368(8):719-727

17. Rona KA, Reynolds J, Schwameis K, Zehetner J, Samakar K, Oh P (2017) Efficacy of magnetic sphincter augmentation in patients with large hiatal hernias. Surg Endosc 31(5):2096-2102

18. Buckley FP, Bell RCW, Freeman K, Doggett S, Heidrick R (2018) Favorable results from a prospective evaluation of 200 patients with large hiatal hernias undergoing LINX magnetic sphincter augmentation. Surg Endosc 32(4):1762-1768

19. Komatsu Y, Hoppo T, Jobe BA (2013) Proximal reflux as a cause of adult-onset asthma: the case for hypopharyngeal impedance testing to improve the sensitivity of diagnosis. JAMA Surg 148(1):50-58

20. Hoppo T, Komatsu Y, Jobe BA (2014) Gastroesophageal reflux disease and patterns of reflux in patients with idiopathic pulmonary fibrosis using hypopharyngeal multichannel intraluminal impedance. Dis Esophagus 27(6):530-537

21. Hoppo T, Sanz AF, Nason KS, Carroll TL, Rosen C, Normolle DP, Jobe BA (2012) How much pharyngeal exposure is "normal"? Normative data for laryngopharyngeal reflux events using hypopharyngeal multichannel intraluminal impedance (HMII). J Gastrointest Surg 16(1):16-25

22. Velanovich V (2007) The development of the GERD-HRQL symptom severity instrument. Dis Esophagus 20(2):130-134

23. Belafsky PC, Postma GN, Koufman JA (2002) Validity and reliability of the reflux symptom index (RSI). J Voice 16(2):274-277

24. Ayazi S, Crookes PF (2010) High-resolution esophageal manometry: using technical advances for clinical advantages. J Gastrointest Surg 14(Suppl 1):S24-S32

25. Ayazi S, Lipham JC, Portale G, Peyre CG, Streets CG, Leers JM et al (2009) Bravo catheter-free $\mathrm{pH}$ monitoring: normal values, concordance, optimal diagnostic thresholds, and accuracy. Clin Gastroenterol Hepatol 7(1):60-67

26. Lord RVN, Kaminski A, Oberg S, Bowrey DJ, Hagen JA, DeMeester SR, DeMeester TR (2002) Absence of gastroesophageal reflux disease in a majority of patients taking acid suppression medications after Nissen fundoplication. J Gastrointest Surg 6(1):3-9

27. Alln PR (1951) Reflux esophagifis, sliding hiatal hernia, and the anatomy of repair. Surg Gynecol Obstet 92:419-431

28. Cohen S, Harris LD (1972) The lower esophageal sphincter. Gastroenterology 63:1066-1073

29. Fein M, Ritter MP, DeMeester TR, Oberg S, Peters JH, Hagen JA et al (1999) Role of the lower esophageal sphincter and hiatal hernia in the pathogenesis of gastroesophageal reflux disease. J Gastrointest Surg 3(4):405-410

30. Oelschlager BK, Pellegrini CA, Hunter JG et al (2011) Biologic prosthesis to prevent recurrence after laparoscopic paraesophageal hernia repair: long-term follow-up from a multicenter, prospective, randomized trial. J Am Coll Surg 213(4):461-468

31. Braghetto I, Korn O, Csendes A, Burdiles P, Valladares H, Brunet L (2010) Postoperative results after laparoscopic approach for treatment of large hiatal hernias: is mesh always needed? Is the addition of an antireflux procedure necessary? Int Surg 95:80-87

32. Zaninotto G, Portale G, Costantini M, Fiamingo P, Rampado S, Guirroli E, Nicoletti L, Ancona E (2007) Objective follow-up after laparoscopic repair of large type III hiatal hernia. assessment of safety and durability. World J Surg 31:2177-2183

33. Stirling MC, Orringer MB (1986) Surgical treatment after the failed antireflux operation. J Thorac Cardiovasc Surg 92:667-672 
34. Hunt J, Williams D, Ungersbock A, Perrin S (1994) The effect of titanium debris on soft tissue response. J Mater Sci: Mater Med 5:381-383

35. Molena D, Mungo B, Stem M, Feinberg RL, Lidor AO (2014) Outcomes of operations for benign foregut disease in elderly patients: a National Surgical Quality Improvement Program database analysis. Surgery 156(2):352-360
Publisher's Note Springer Nature remains neutral with regard to jurisdictional claims in published maps and institutional affiliations. 